\title{
Two Patients with Chronic Pancreatitis Complicated by a Pancreaticopleural Fistula
}

\author{
Jordy J.S. Kiewiet ${ }^{\mathrm{a}} \quad$ Marlous Moret $^{\mathrm{b}} \quad$ Willem L. Blok $^{\mathrm{b}}$ \\ Michael F. Gerhards ${ }^{\mathrm{a}}$ Laurens T. de Wit ${ }^{\mathrm{a}}$

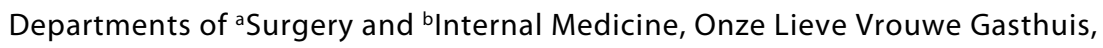 \\ Amsterdam, The Netherlands
}

\section{Key Words}

Pancreaticopleural fistula - Chronic pancreatitis · Treatment

\begin{abstract}
Two patients presented with dyspnea and signs of chronic pancreatitis. Patient $B$ had pleural effusion on chest $X$-ray. Patient A developed pleural effusion during the course of disease. On further analysis these pleural effusions showed elevated amylase concentrations. This finding suggested the diagnosis of a pancreaticopleural fistula which was confirmed by magnetic resonance cholangiopancreatography. Because of the distinct localization of the fistulas the patients were treated differently. In patient A an endoprosthesis was successfully placed in the pancreatic duct, and patient $B$ underwent distal pancreatic resection. Considering the rarity of pancreaticopleural fistula, there is no consensus on diverse aspects of treatment, such as length of treatment with octreotide. However, a rationale for the distinction between fistulas suited for treatment with endoprosthesis or surgery seems to provide some grip.
\end{abstract}

\section{Introduction}

A pancreaticopleural fistula is a rare complication of chronic pancreatitis. In the literature various therapeutic modalities have been described: inhibition of the exocrine function of the pancreas with drugs (octreotide), endoscopic stenting of the pancreatic duct, and surgical removal of (part of) the pancreas. In this case report we present two patients and discuss the various therapies in more detail. 


\section{Cases}

\section{Patient A}

A 58-year-old man with a history of a situs inversus totalis, alcohol abuse, hypertension and peripheral vascular disease came to the emergency ward with abdominal pain since three weeks. Physical examination showed no abnormalities besides local abdominal pain during palpation of the epigastric region. Blood samples showed the following values: WBC $23.5 \times 10^{9} / 1\left(4-10 \times 10^{9} / 1\right)$, thrombocytes $467 \times 10^{9} / \mathrm{l}\left(150-400 \times 10^{9} / \mathrm{l}\right)$, albumin $28 \mathrm{~g} / \mathrm{l}(35-50 \mathrm{~g} / \mathrm{l})$, alkaline phosphatase $233 \mathrm{IU} / \mathrm{l}$ (<120 IU/l), $\gamma$-GT $145 \mathrm{IU} / 1$ (<55 IU/l), LDH $232 \mathrm{IU} / \mathrm{l}(<250 \mathrm{IU} / \mathrm{l})$, SGPT 86 IU/l $(<40 \mathrm{IU} / \mathrm{l})$, SGOT $62 \mathrm{IU} / \mathrm{l}(<35 \mathrm{IU} / \mathrm{l})$, total bilirubin $14 \mu \mathrm{mol} / \mathrm{l}(<17 \mu \mathrm{mol} / \mathrm{l})$, amylase $336 \mathrm{IU} / \mathrm{l}(<50 \mathrm{IU} / \mathrm{l})$, triglyceride $1.97 \mathrm{mmol} / \mathrm{l}(0.6-2.2 \mathrm{mmol} / \mathrm{l}), \mathrm{CRP} 192 \mathrm{mg} / \mathrm{l}(<10 \mathrm{mg} / \mathrm{l})$. A chest X-ray showed a situs inversus totalis without signs of pleural effusion. The patient was admitted under suspicion of acute pancreatitis. Ultrasonography of the abdomen showed a circumscriptive loculation of fluid around the liver. An additional abdominal CT scan showed intracapsular fluid loculation in the liver and no abnormalities of the pancreas (fig. 1). The loculated fluid was aspirated with ultrasonography guidance revealing $1,600 \mathrm{ml}$ green-yellow fluid. The bilirubin level in this fluid was $7 \mu \mathrm{mol} / \mathrm{l}$ and showed no bacterial growth; amylase levels where not determined. After aspiration epigastric pain subsided and the patient was discharged.

A week later he returned to the emergency department with dyspnea and pain in the upper right quadrant and flank. Physical examination showed a breathing frequency of $45 / \mathrm{min}$ and a saturation of $97 \%$ without supportive oxygen. Percussion of the thorax was muffled from the basis of the thorax until the sixth thoracic vertebra on the left side. Inherently there were no breathing sounds on auscultation. The abdomen was supple, but on palpation there was pain in the right upper quadrant. New blood samples revealed the following: WBC $19.0 \times 10^{9} / 1\left(4-10 \times 10^{9} / 1\right)$, thrombocytes $447 \times 10^{9} / 1(150-400 \times$ $\left.10^{9} / \mathrm{l}\right)$, alkaline phosphatase $176 \mathrm{IU} / \mathrm{l}(<120 \mathrm{IU} / \mathrm{l}), \gamma$-GT $90 \mathrm{IU} / \mathrm{l}(<55 \mathrm{IU} / \mathrm{l}), \mathrm{LDH} 282 \mathrm{IU} / \mathrm{l}(<250 \mathrm{IU} / \mathrm{l})$, SGPT $64 \mathrm{IU} / \mathrm{l}(<40 \mathrm{IU} / \mathrm{l})$, SGOT $43 \mathrm{IU} / \mathrm{l}(<35 \mathrm{IU} / \mathrm{l})$, total bilirubin $15 \mu \mathrm{mol} / \mathrm{l}(<17 \mu \mathrm{mol} / \mathrm{l})$, amylase $464 \mathrm{IU} / \mathrm{l}(<50 \mathrm{IU} / \mathrm{l}), \mathrm{CRP} 385 \mathrm{mg} / \mathrm{l}(<10 \mathrm{mg} / \mathrm{l})$. Chest X-ray showed elevation of the left hemidiaphragm accompanied by some bilateral atelectasis and pleural effusion. The patient was readmitted under suspicion of having a relapse of the fluid loculation in the liver possibly complicated by an infection. Ultrasonography of the abdomen confirmed the suspicion, showing a relapse of the fluid collection which was drained at once. The obtained fluid showed the following values: bilirubin $10 \mu \mathrm{mol} / \mathrm{l}, \mathrm{WBC}$ $116.7 \times 10^{9} / \mathrm{l}$, albumin $7 \mathrm{~g} / \mathrm{l}$, total protein $19 \mathrm{~g} / \mathrm{l}$, LDH 24,696 IU/l, amylase 40,782 IU/l. More than 1,000 colonies of Streptococcus milleri were cultured. One day following the drainage the patient developed respiratory insufficiency and was admitted to the intensive care unit. He developed a vast amount of pleural effusion on the right side which was drained by thoracocentesis. The highest level of amylase in the pleural effusion was 70,584 IU/l. In this effusion no bacteria were isolated. Subsequently a magnetic resonance cholangiopancreatography (MRCP) was performed where a fistula was identified originating from the proximal pancreatic duct and ending in a fluid collection located adjacent to the diaphragm. This fluid collection had a close relation to the intracapsular fluid collection in the liver (fig. 2). The high levels of amylase in the fluid collection in the liver and in the pleural effusion strongly suggested that there was a continuum between the identified pancreatic fistula, the pleural cavity and the fluid collection in the liver. Octreotide therapy was started to inhibit the exocrine function of the pancreas. Already antibiotics were administered since the culture had grown Streptococcus. Since the fistula had its origin in the proximal pancreatic duct, an endoprosthesis was placed covering the origo by endoscopic retrograde cholangiopancreatography. After long-term admission of 28 days in the ICU the patient was transferred to the surgical ward. Slowly his clinical condition improved and he was discharged to a nursing home for revalidation 43 days after the endoprosthesis was placed.

\section{Patient B}

Patient B was a 58-year-old male. In the past he had been hospitalized several times for alcohol abuse-induced gastritis and dehydration. Two months prior to presentation at our hospital he had been analyzed elsewhere for complaints of dyspnea. A large volume of pleural effusion had been drained containing an elevated concentration of amylase A. CT scan of the abdomen was performed showing pseudocysts in the upper left quadrant. Recurrent complaints of dyspnea were the reason to consult our hospital. In addition to the dyspnea he reported abdominal pain in the upper right quadrant for several years which had increased markedly during the last few weeks. At the time of presentation the patient had been sober for a prolonged period. On physical examination we saw a cachectic man not looking acutely ill. Blood samples revealed the following values: white blood cell count (WBC) $8.9 \times 10^{9} / 1$ (4- 
$\left.10 \times 10^{9} / \mathrm{l}\right)$, thrombocytes $455 \times 10^{9} / 1\left(150-400 \times 10^{9} / \mathrm{l}\right)$, albumin $37 \mathrm{~g} / \mathrm{l}(35-50 \mathrm{~g} / \mathrm{l})$, alkaline phosphatase $103 \mathrm{IU} / \mathrm{l}(<120 \mathrm{IU} / \mathrm{l}), \gamma$-GT $28 \mathrm{IU} / \mathrm{l}(<55 \mathrm{IU} / \mathrm{l}), \mathrm{LDH} 178 \mathrm{IU} / \mathrm{l}(<250 \mathrm{IU} / \mathrm{l}), \mathrm{SGPT} 7 \mathrm{IU} / \mathrm{l}(<40 \mathrm{IU} / \mathrm{l}), \mathrm{SGOT}$ $20 \mathrm{IU} / \mathrm{l}(<35 \mathrm{IU} / \mathrm{l})$, total bilirubin $6 \mu \mathrm{mol} / \mathrm{l}(<17 \mu \mathrm{mol} / \mathrm{l})$, amylase $438 \mathrm{IU} / \mathrm{l}(<50 \mathrm{IU} / \mathrm{l})$, CRP $11 \mathrm{mg} / \mathrm{l}$ $(<10 \mathrm{mg} / \mathrm{l})$. Plain chest radiography revealed a substantial amount of left-sided pleural effusion. Under suspicion of pancreatitis the patient was admitted to the hospital, the pleural effusion thought to be either reactive or caused by a pancreaticopleural fistula. The amylase level in the drained pleural effusion was 16,065 IU/l. Focal pancreatitis of the tail was seen on MRCP. The distal pancreatic duct was deformed and a fistula tract was identified communicating with one of the pseudocysts (fig. 3 ). This pseudocysts lay in close relation with the left hemidiaphragm and expansion to the pleural cavity was suspected. Following these findings octreotide therapy was started. After multidisciplinary deliberation the choice was made to perform a distal pancreatectomy. Perioperatively the clinical diagnosis of pancreatitis with pseudocysts was confirmed. A fistula was identified originating from one of the pseudocysts and ending at the hiatus aortae. Considering the extent of the pseudocysts and the pancreatitis infiltrate a splenectomy was also performed. The postoperative course was uneventful and the patient was discharged after eight days.

\section{Discussion}

Pancreaticopleural fistulas are a rare complication of chronic pancreatitis. The incidence in series described in the literature lies between 0.4 and $4.5 \%$ of patients having pancreatitis $[1,2]$. Fistulas can arise following trauma or surgical procedure of the pancreas. The pathophysiological mechanism in chronic pancreatitis most probably consists of leakage from a pseudocyst or rupture of the pancreatic duct [3]. Most of the patients have a history of alcohol abuse (70-100\%). Age at diagnosis varies from 20 to 60 years $(95 \%)[4]$.

Dyspnea, coughing and thoracic pain are the predominant symptoms in pancreaticopleural fistulas. Only $24 \%$ of the patients have accompanying abdominal pain [5]. In the described cases both patients had abdominal symptoms, however the pulmonary complaints were the most prominent. Pleural effusions frequently recur after drainage and are localised unilateral (left-sided) in $76 \%$ of the cases [6].

When patients have signs of chronic pancreatitis accompanied by pleural effusion, the possibility of a pancreaticopleural fistula must always be considered. Although it is an uncommon entity, the diagnosis can be made fairly easily by determining the concentration of amylase in pleural effusion [4]. Radiological imaging is available to sustain the diagnosis. MRCP seems to be the imaging modality of choice because of its superiority to $\mathrm{CT}$ in indentifying a fistula in the pancreatic region. Its noninvasive character is an advantage compared to endoscopic retrograde cholangiopancreatography $[7,8]$.

The first line of treatment options in pancreatic fistulas is the inhibition of the exocrine function of the pancreas by octreotide. The use of octreotide in gastrointestinal fistulas proved to reduce the time until closure and morbidity [9]. Specific rates of successful closure for pancreaticopleural fistulas have not yet been reported, however positive effects have been demonstrated [10]. The expanding knowledge of the pathogenesis of chronic pancreatitis has led to the identification of new molecular targets and subsequent therapeutic agents which might also prove beneficial in pancreatic fistulas. However, until now there are no reports of trials in humans reproducing the beneficial effect found in animal models [11]. Besides pharmacological intervention thoracocentesis is recommended. There is no consensus whether or not measures must be taken to prevent food and fluids passing the duodenum. Lamme et al. for instance advise enteral feeding through a nasojejunal tube [4], Safadi and Marks advise total parenteral nutrition [12], whereas Dhebri and Ferran consider neither of these measures meaningful [3]. The 
duration of treatment with octreotide until the point it should be considered unsuccessful is also subject of debate. In general a period of 3-4 weeks is accepted [13]. Despite adequate drainage and treatment with octreotide there was no clinical improvement in patient A. Therefore an endoprosthesis was placed in the pancreatic duct. The positive effect of this procedure is not only attributed to the direct covering of the origin of the fistula, but also to the decrease in pressure in the pancreatic duct $[3,13,14]$. The distinction between fistulas suited for treatment with endoprosthesis and those requiring surgery is of great importance. The following three characteristics of the fistula are the limitations to the use of endoprosthesis. First the orirgin of the fistula must not be located in the distal segment of the pancreatic duct, second the duct must not be totally ruptured, and third there must be no obstruction of the duct leading to the impossibility to place a stent. If patients do not have these limitations, the rate of success with endoprosthesis is high $[3,13-16]$. There is no uniform opinion on how long the endoprosthesis should rest in place, there are reports ranging from 4 weeks up to 6 months $[6,12]$. For the remaining patients surgical intervention is the appropriate treatment option [17]. Patient B underwent a distal pancreatectomy and splenectomy since the fistula was located in the distal part of the pancreatic duct. The lack of long-term follow-up for treatment with endoprosthesis as well as for surgery is the reason no accurate data are available on the recurrence of either treatment. The follow-up treatment with octreotide is again subject of discussion, recommendations ranging from a few weeks to several months [9].

\section{Conclusion}

Pancreaticopleural fistulas are a rare condition, but need to be considered in every patient with signs of chronic pancreatitis and pleural effusion. The diagnosis can be made by determination of the amylase concentration in pleural effusion and can be confirmed by MRCP. Having diagnosed a patient with a pancreaticopleural fistula, octreotide is the obvious treatment to start with. If the symptoms do not subside the placement of an endoprosthesis or surgical intervention might be appropriate. The choice of either of these treatment modalities depends on the characteristics of the fistula, such as location or extent. 


\begin{tabular}{r|l|l|l} 
Case Reports in & $\begin{array}{l}\text { Case Rep Gastroenterol 2009;3:36-42 } \\
\text { D0I: 10.1159/000210442 }\end{array}$ & Published online: April 7, 2009 & $\begin{array}{l}\text { O 2009 S. Karger AG, Basel } \\
\text { ISSN 1662-0631 } \\
\text { www.karger.com/crg }\end{array}$ \\
\hline
\end{tabular}

Fig. 1. Patient A: Coronal image of a CT scan depicting the fluid collection in the liver.

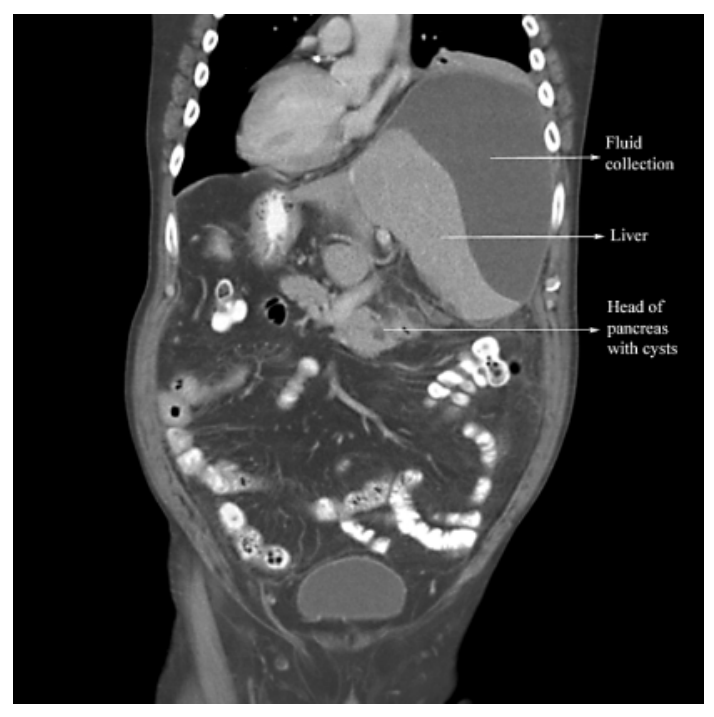

Fig. 2. Patient A: Coronal image of a MRCP depicting the fistula originating from the proximal pancreatic duct ending in a pseudocyst located just below the diaphragm.

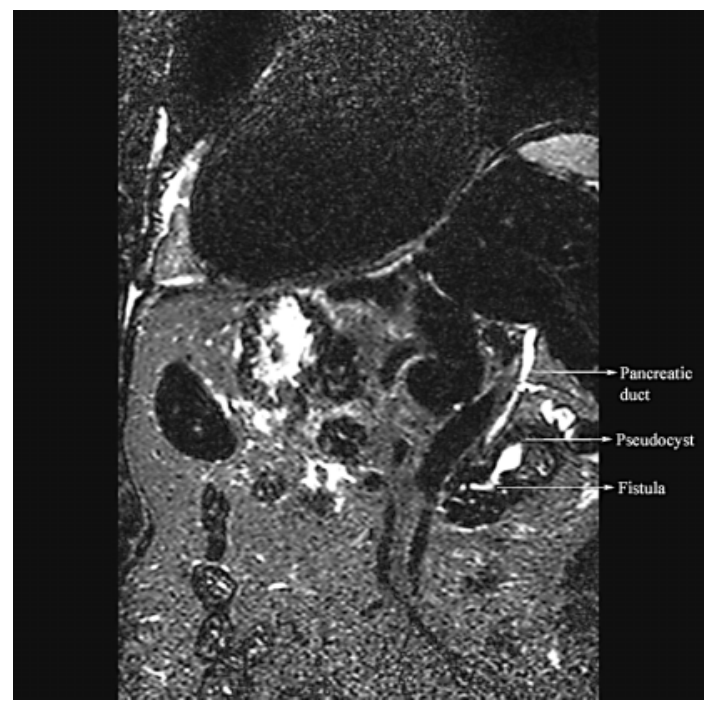




\begin{tabular}{r|l|l|l} 
Case Reports in & $\begin{array}{l}\text { Case Rep Gastroenterol 2009;3:36-42 } \\
\text { D0I: 10.1159/000210442 }\end{array}$ & Published online: April 7, 2009 & $\begin{array}{l}\text { O 2009 S. Karger AG, Basel } \\
\text { ISSN 1662-0631 } \\
\text { www.karger.com/crg }\end{array}$ \\
\hline
\end{tabular}

Fig. 3. Patient B: Axial MRCP image showing the deformed distal pancreatic duct and the fistula and the close relation with the pseudocysts.

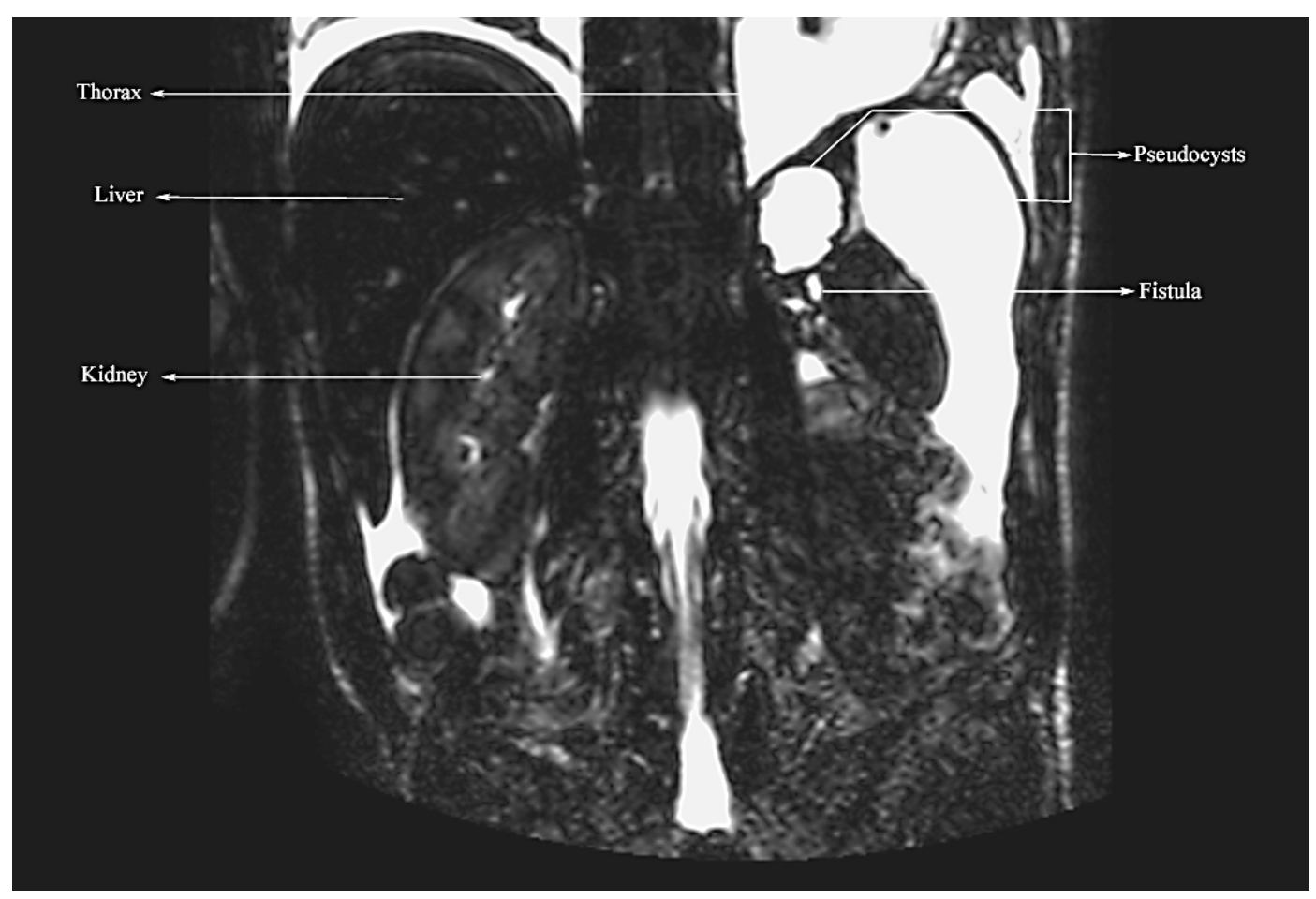




\section{References}

1 Rockey DC, Cello JP: Pancreaticopleural fistula. Report of 7 patients and review of the literature. Medicine (Baltimore) 1990;69:332-344.

-2 Pottmeyer EW 3rd, Frey CF, Matsuno S: Pancreaticopleural fistulas. Arch Surg 1987;122:648-654.

-3 Dhebri AR, Ferran N: Nonsurgical management of pancreaticopleural fistula. JOP 2005;6:152-161.

4 Lamme B, Boerma D, Boermeester MA, Gouma DJ: Pleural fluid in chronic pancreatitis (in Dutch). Ned Tijdschr Geneeskd 2003;147:1437-1441.

5 Uchiyama T, Suzuki T, Adachi A, Hiraki S, Iizuka N: Pancreatic pleural effusion: case report and review of 113 cases in Japan. Am J Gastroenterol 1992;87:387391.

6 Hastier P, Rouquier P, Buckley M, Simler JM, Dumas R, Delmont JP: Endoscopic treatment of wirsungo-cysto-pleural fistula. Eur J Gastroenterol Hepatol 1998;10:527-529.

7 Materne R, Vranckx P, Pauls C, Coche EE, Deprez P, Van Beers BE: Pancreaticopleural fistula: diagnosis with magnetic resonance pancreatography. Chest 2000;117:912-914.

8 Otsuki M: Chronic pancreatitis. The problems of diagnostic criteria. Pancreatology 2004;4:28-41.

-9 Torres AJ, Landa JI, Moreno-Azcoita M, et al: Somatostatin in the management of gastrointestinal fistulas. A multicenter trial. Arch Surg 1992;127:97-99.

10 Talukdar R, Saikia N, Singal DK, Tandon R: Chronic pancreatitis: Evolving paradigms. Pancreatology 2006;6:440-449.

-11 Safadi BY, Marks JM: Pancreatic-pleural fistula: the role of ERCP in diagnosis and treatment. Gastrointest Endosc 2000;51:213-215.

12 Lipsett PA, Cameron JL: Internal pancreatic fistula. Am J Surg 1992;163:216-220.

13 Shah HK, Shah SR, Maydeo AP, Pramesh CS: Pancreato-peural fistula. Endoscopy 1998;30:314.

14 Chan KL, Lau WY, Sung JY: Octreotide therapy for pancreaticopleural fistula. J Gastroenterol Hepatol 1994;9:530-532.

15 Miyachi A, Kikuyama M, Matsubayashi Y, et al: Successful treatment of pancreaticopleural fistula by nasopancreatic drainage and endoscopic removal of pancreatic duct calculi: a case report. Gastrointest Endosc 2004;59:454-457.

16 Koshitani T, Uehara Y, Yasu T, et al: Endoscopic management of pancreaticopleural fistulas: a report of three patients. Endoscopy 2006;38:749751.

17 Cunha JEM, Penteado S, Jukemura J, et al: Surgical and interventional treatment of chronic pancreatitis. Pancreatology 2004;4:540-550. 